\title{
LA AGRICULTURA EN EL LABERINTO POLÍTICO DE IBEROAMÉRICA
}

\author{
Eusebio García MANRiQue
}

\begin{abstract}
RESUMEN
En los últimos cuarenta años la agricultura de los países iberoamericanos ha sufrido profundos cambios. Su entrada en las redes del comercio internacional favoreció la desaparición del sistema tradicional latifundio-precarista heredado de la época colonial. Dos sistemas predominaron en esa transformación: el de la reforma agraria que eliminó los latifundios o el de la modernización de las grandes explotaciones de productos de exportación, con tardíos intentos de pequeñas reformas agrarias. En ambos casos el resultado ha sido la presencia de dos tipos de agricultura, dentro de cada país: una bien preparada para la globalización y otra marginada en el interior y frente al mercado exterior.
\end{abstract}

\section{ABSTRAT}

In the last forty years the agriculture of the Latin American countries has undergone deep changes. Its entrance in the networks of the international trade favored the disappearance of the traditional system inherited large estate-precarista of the colonial time. Two systems predominated in that transformation: the one of the agrarian reform that eliminated the large estates or the one of the modernization of the great export product exploitations, with delayed attempts of small agrarian reforms. In both cases the result has been the presence of two types of agriculture, inside each country: one prepared for the globalization and marginalized other in the interior and in front of the outer market well.

La reciente nacionalización del petróleo boliviano por el nuevo presidente Evo Morales y su repercusión en la empresa española Repsol que junto con la brasileña Petrobras tenían la explotación directa de los principales yacimientos de gas, ha motivado un cierto interés español sobre la situación cambiante de las políticas del continente iberoamericano. El nuevo eje Cuba, Venezuela, Bolivia, con la firma del reciente acuerdo ALBA (Alternativa Bolivariana para las Américas) y las expectativas sobre las próximas elecciones en México y Nicaragua, con candidatos caudillistas opuestos a los convenios 
con USA, dibuja un futuro de alianzas en Iberoamérica de rechazo frontal a la política norteamericana, aunque frustradas por el triunfo de Alan García sobre Ollanta Humanes, en Perú.

Este trasfondo de "alta política" se entremezcla con los problemas de estructuras agrarias.. La política de Evo Morales, defensor tradicional de la legalización de los cultivos de coca bolivianos, de uso secular en el país y su nueva reforma agraria (aunque mirada con reticencia por el gobierno local de Santa Cruz de la Sierra) y los ataques del presidente venezolano a la Asociación del Mercado Libre Americano, donde los problemas agrarios son el elemento base, viene a unirse al rechazo de colectivos agrarios contra esos contratos bilaterales a los que acusan de desorganizar todavía más las estructuras agrarias de sus países ${ }^{1}$.

Durante cuarenta años se han hecho esfuerzos en el continente americano por acercar sus economías e integrarlas en grandes tratados, en clave agraria sobre todo, algo que en estos momentos se está estancando por razones ideológicas. Y con ello se frustra la posibilidad de presentarse como un bloque, con fuerte potencialidad de discusión, en las diferentes rondas que se celebran periódicamente sobre la liberalización del comercio internacional, que para Iberoamérica, es básicamente de productos agrarios. Un ejemplo de esta división se manifestó negativamente en la reunión de Viena, con la UE, en el mes de mayo.

Han sido muchos los intentos de alianza promovidos dentro de los estados iberoamericanos sobre asuntos económicos. Solo enumeramos los que presentan una gran importancia.

En un primer intento de identidad y organización colectiva, surgió en 1948 la OEA (Organización de Estados Americanos) creada en 1948, bajo la dirección de Estados Unidos, el gran vencedor de la segunda guerra mundial. Poco después, un grupo de países centroamericanos fundó la ODECA (Organización de Estados Centroamericanos) en1951.

Ante el ejemplo del Mercado Común europeo (1957), se intentó avanzar en 1960 con la creación de un Mercado Común americano (Asociación Latinoamericana de Libre Comercio (ALALC) integrada por Argentina, Brasil, Chile, México, Paraguay, Perú y Uruguay. Al año siguiente se incorporaron Ecuador y Colombia y en 1 966-7, Venezuela y Bolivia. La ALALC pretendía rebajar o eliminar las barreras aduaneras entre los estados, pero no se logró aprobar un arancel exterior común, aunque preveía medidas para coordinar

1. La actualidad de esta problemática me mueve a realizar este trabajo en el que agrego datos y reflexiones, extraídos de la práctica de una larga tarea docente sobre la materia, como homenaje a Isabel Pérez de Colosía que compite la pasión por Iberoamérica y que me honra con su amistad. 
políticas internas. De hecho solo se buscaban pactos entre dos o tres países y sobre productos concretos. Un ejemplo fue el "grupo de los tres" integrado por Colombia, México y Venezuela

En 1995, EE.UU intentó la creación del ALCA (Área de libre comercio americano), pero la negativa de EE.UU a suprimir las subvenciones a sus agricultores, provocó una oposición cerrada de varios países. De hecho solo se pasó a acuerdos bilaterales (TLC) con Centroamérica, México, Chile y, recientemente, los que se están negociando con Perú y Colombia y posiblemente con Uruguay.

En 1969 se había iniciado el "pacto de Cartagena" que en un largo proceso terminó en la creación en 1997 del CAN (Comunidad Andina de Naciones) formada por Bolivia, Colombia, Ecuador, Perú y Venezuela. Se pretendía una cierta integración económica, con eliminación de aranceles y política común sobre infraestructuras. Igualmente, después de años de relaciones previas, se fundó en 1991 Mercosur que engloba a Brasil, Argentina, Paraguay, Uruguay y, como estados asociados, Chile y Bolivia

Finalmente, en diciembre del 2004, en el Cuzco, se creó la Comunidad Sudamericana de Naciones que integraba al grupo del CAN con Mercosur, además de Chile, para un acuerdo de libre comercio, a lo que se agregó el IIRSA (Integración de Infraestructura regional de América del sur) que haría posible los planes de comunicación que unirían el interior de Brasil con los puertos del sur de Perú. En todos estos tratados, el comercio de los productos agrarios figura como prioritario. La recién formada Comunidad Sudamericana de Naciones intenta presentar un frente común unido, en las rondas que se suceden sobre la liberalización del comercio mundial.

Pero actualmente, al año y medio de la cumbre de el Cuzco, la Unión sudamericana, que teóricamente ha ido a Viena a tratar con la UE como un bloque, está amenazada de romperse en pedazos. Las causas no han sido económicas, sino ideológicas.

Primero incidió el apoyo financiero del presidente Chávez al candidato peruano Ollanta Humala y la amenaza de romper sus relaciones con ese país si ganase las elecciones su opositor Alan García, lo que provocó la protesta enérgica de Toledo, entonces presidente peruano. Lo mismo ocurre con respecto a México y Nicaragua, donde financia a los candidados Lopez Obrador y Daniel Ortega. El escaso margen con que ha ganado las elecciones Felipe Calderón frente a López Obrador y el rechazo de éste a aceptarle como vencedor, complicará la presidencia de Calderón en el futuro y la petición de Chávez de dotar a Bolivia de su antigua salida al mar, un corredor que perdió en 1879, en la guerra del salitre, ha provocado la ruptura de relaciones por parte de Chile.

La firma por parte de Colombia y Perú del tratado de libre comercio bilateral (TLC) con EE.UU hizo que, en abril del 2006, Venezuela abandonase la 
CAN con lo cual se dislocaba la Comunidad Sudamericana de Naciones, fundada en el Cuzco hacía 16 meses. Igualmente el presidente Chávez ha anunciado, el mes de mayo, que se separaba del "grupo de los tres" México, Colombia y Venezuela que mantenían un acuerdo comercial. Además, Argentina pone reticencias al proyecto acordado con Uruguay de construir un gasoducto que llegase desde Bolivia atravesando Paraguay.

Al margen de ideologías, el contencioso, dentro de Mercosur, por la instalación en Uruguay de dos papeleras, de capital finlandés y español, es contestada frontalmente por Argentina a causa de la contaminación que conllevará el río común y han decidido ambos llevar el caso al tribunal de La Haya. Uruguay, por su parte, ha anunciado que posiblemente firmará un tratado de libre comercio con EE.UU porque apenas recibe beneficios en Mercosur.

La realidad es que fuera de rebajas de aranceles, pero sin una integración de estructuras y legislaciones, se ha hecho poco en este largo período en los intentos por acercar sus economías. Se puede, solo en parte, comprender este retraso porque, desde mediados de los sesenta hasta mediados de los ochenta, todos los estados iberoamericanos estuvieron centrados solamente en realizar profundos cambios dentro de su territorio, donde la organización agraria era el proyecto líder, pues ocupaba la mayor parte de la población. Los resultados fueron contradictorios y su intento de romper la arcaica e injusta situación agraria, produjo en casi todos, una disociación dentro de sus economías. Un nuevo cambio se produjo a partir de la década de los noventa con la globalización, los avances de la tecnología y libertad de movimiento de capitales, que dio por resultado una rápida agroindustrialización y el aumento de importancia del sector agroalimentario en Iberoamérica, pero en el que solo se ha integrado un sector dinámico, mientras se margina a una gran masa de agricultores.

Actualmente para todo el conjunto de Iberoamérica, el sector primario de agricultura, silvicultura y pesca representa el 7,5\% del producto interior bruto (con excepciones, como Colombia con el 13,8 \%, Bolivia con el 14,2 \% y Paraguay con el 27,6 \%) cuando la población rural, después de un éxodo masivo a las ciudades, representaba en 1980 el $25 \%$ de la población total. Pero si le agregamos el sector agroindustrial, contribuye al PIB en un $25 \%$ y en las exportaciones totales representa el $40 \%$ a pesar de la importancia, en algunos países, de los productos minerales y energéticos. Si analizamos individualmente a los países, las exportaciones pueden representar valores del $80 \%$.

Según las estadísticas de 1997 vivían en el mundo rural iberoamericano 111 millones y de ellos 78 millones estaban bajo la línea de la pobreza. Eso en un continente que posee el $25 \%$ de las tierras cultivables del mundo. Si consideramos el conjunto de la población, de los 523 millones de habitantes que tenía Iberoamérica en el 2000, el $43 \%$, unos 220 millones, vivían en la pobreza y de ellos, 95 millones eran indigentes. 
Consideramos por eso útil una reflexión sobre el modo como se han desarrollado las políticas agrarias en los últimos cuarenta años, en su intento de sacar a sus agricultores del subdesarrollo e insistir en que, el resultado ha sido lamentablemente, la coexistencia dentro de cada país, salvo alguna excepciones, de una agricultura dual, una de desarrollo y otra en regresión, lo que ha propiciado enfrentamientos internos y resultados contradictorios en su apertura al exterior. Un análisis de esas diferentes trayectorias hace comprensible que hasta ahora no se haya logrado la deseada integración en un bloque único común, frente a los grandes bloques, el norteamericano y el europeo.

Para seguir este proceso hay que partir de la situación del agro iberoamericano a mediados del siglo XX y analizar las transformaciones inducidas en sus agriculturas en los 20 años que van desde mediados de los sesenta a mediados de los ochenta, pues el resultado de estos cambios está presente y dificulta los intentos de modificarlos. Dos hechos hay que tener presente en la lectura. Primero que, en un breve artículo solo se pueden poner unos ejemplos y estos de modo esquemático y es conocido que un esquema lleva incorporado indefiniciones y omisiones. Y en segundo lugar, como algo esencial, este análisis debe tener como fondo, la evolución de la población. En algunos casos tendremos que preguntarnos ique crecimiento económico continuado tenía que haber tenido Brasil -arrancando de un subdesarrollo- si en cincuenta años pasó de una población de 53 millones en 1950 a 170 en el año 2000, o México que en las mismas fechas pasó de 25,7 millones a 97,5 millones?

Otro problema importante hay que tener en cuenta: el abandono por parte de EE.UU. Durante la segunda guerra mundial Iberoamérica colaboró al triunfo de los aliados con sus recursos mineros, petróleo, cobre, estaño y sus productos agrícolas. Por eso, al terminar la guerra, todos esperaban que había llegado la "hora de Iberoamérica" para su desarrollo con la ayuda financiera americana. Pero el peligro del comunismo, en una Europa en ruinas por la guerra, orientó a EE.UU a decidir que era la hora de Europa, con el Plan Marshall. Solo cuando estuvo reconstruida Europa y ante el miedo al contagio de la revolución cubana, el presidente Kennedy ofreció a los gobiernos iberoamericanos reunidos en Punta del Este (en 1961) la "Alianza para el progreso" que comportaba ayudas financieras y lanzó la idea de reformas agrarias controladas. Pero el asesinato de Kennedy dejó vacío el proyecto.

\section{LA AGRICULTURA IBEROAMERICANA A MEDIADOS DEL SIGLO XX}

En esas fechas, la situación de la agricultura iberoamericana era fruto de una herencia colonial no modificada a pesar de los 150 años transcurridos 
desde su independencia. Predominaba el latifundio tradicional, relacionado con un minifundio precario y dependiente.

El esquema era sencillo. El propietario entregaba, para su subsistencia, a un grupo de agricultores, una parte de su tierra generalmente en zonas marginales, con la obligación de trabajar gratis en la finca del señor durante determinados días y, en la época de recogida de la cosecha, toda su familia. Era una situación precaria, sin contrato y dependiendo del señor. No podían cultivar productos comerciales en esas parcelas, pues entrarían en competencia con los del dueño.

En la época de recogida se buscaban además obreros entre minifundistas independientes cuya explotación no les bastaba para vivir o en los abundantes asalariados sin tierra. En el NE de Brasil llamaban "corvao" ( yugo) a este sistema en las plantaciones de caña. En otros sitios eran arrendires, allegados, yasipungueros, etc. En las haciendas ganaderas, el colono recibía un pequeño lote con la condición de cuidar el ganado del señor. Si el señor quería plantar árboles de café, cacao o plátanos se le entregaba una parcela a un "redimidor"donde plantaba los árboles y en la cual cultivaba para su subsistencia, hasta que al crecer los árboles se entregaba la plantación al señor. En la Pampa argentina -donde la gran propiedad había surgido en 1879- era frecuente entregar parcelas extensas para cultivos de trigo y al cabo de tres o cuatro años se devolvía la parcela al señor, pero sembrada de alfalfa.

El sistema tenía una lógica. El propietario tenía tierra abundante -poco dinero en efectivo- y necesidad de mano de obra, para recoger la cosecha en zonas sin comunicaciones para poderlos traer de fuera. Además había un exceso de mano de obra disponible durante el año. Con tal tipo de obreros, la productividad era muy baja, pero como las redes comerciales eran casi inexistentes, un exceso de producción hubiera producido una bajada de los precios

En determinados sitios existía propiedades medias como entre los cafeteros de Costa Rica y de Medellín (Colombia) o los descendientes de la colonización alemana en las zonas altas de Santa Catalina al sur de Sao Paulo en Brasil. Argentina después de la conquista de la Pampa en 1879, Uruguay y Sao Paulo que recibieron contingentes de inmigrantes españoles, italianos y portugueses, siguieron lógicas diferentes. En las tierras del sur de Chile conquistadas las tierras de los antiguos araucanos, los mapuches- se crearon grandes propiedades de chilenos, ingleses y españoles

Pero a partir de 1950-60, con el transporte rápido y barato, se desarrolló un intenso comercio internacional. Con la elevación del nivel de vida de los países industrializados y también de pequeños grupos de población de las ciudades de Iberoamérica, hubo una demanda masiva de productos tropicales. Eso provocó nuevas relaciones sociales, en cuanto a utilización de la fuerza de trabajo, que iban a hundir la relación dueño-precaristas. Se estaba implan- 
tando lo que se llamó la "revolución verde" en busca de productividad. El propietario, ante los nuevos canales de comercialización, quería aumentar la producción y le interesaba tener unos pocos obreros especializados bien pagados, no los antiguos precaristas analfabetos y sin motivación.

Se dieron cuatro procesos:

a) el propietario intentó eliminar al precarista para recuperar la tierra que le había entregado y prescindir de su trabajo inoperante en la hacienda

b) al mismo tiempo, surgió en los precaristas un deseo de estabilidad, de tener condiciones dignas y eliminar el corvao. Deseaban quedarse en propiedad las tierras que cultivaban, pero sin las prestaciones obligatorias de trabajo al hacendado. Aparecieron los pequeños sindicatos locales muy agresivos: en Perú (Héctor 1958 ) en Brasil "las ligas campesinas" en 1955.

c) En 1961, en Punta del Este (Uruguay), Kennedy lanzó la idea de la "Alianza para el Progreso" Se habló por primera vez, por parte americana, de reforma agraria, tabú hasta entonces. (Habían existido, las de México, Bolivia, el intento en Guatemala, pero la de Cuba en 1960 impresionó a América por su radicalidad y el intento de exportarla al continente por el Che Guevara). Los americanos intentaban implantar una reforma agraria controlada, no explosiones radicales, como las de Bolivia y Cuba.

d) Un proceso de industrialización había hecho aparecer una nueva oligarquía industrial, que veía que ese sistema arcaico de utilización de la tierra era contrario a sus intereses de venta de productos. Si los agricultores vivían en la miseria, $¿$ a quién iban a vender sus productos industriales de baja calidad que no se podían exportar?

Proliferaron también los sindicatos en las ciudades. Los intelectuales se adhirieron a la reforma agraria. Se intentaba eliminar la poderosa oligarquía de la tierra y sus latifundios mal cultivados.

Kennedy fue asesinado y los miles de millones de dólares prometidos y necesarios para las reformas no llegaron. Pero la idea de reforma agraria impulsada inicialmente por los norteamericanos se impuso en todos los países Iberoamericanos. Se abrió un proceso de reformas y contra reformas, según predominaba un grupo u otro en el poder.

Por citar algunos ejemplos, es interesante resaltar que los países donde las exportaciones agrarias representaban poco (Perú 17\% y Chile 3\%, pues el principal producto exportador era minero) tuvieron reformas agrarias. Donde las exportaciones agrícolas representaban el 79-80\% (Colombia), el $75 \%$ (Brasil), no hubo reforma. México había comenzado su reforma agraria en 1917. Prácticamente la mayor parte aprobaron planes de reformas con mayor o menor eficacia. Por ejemplo, en Venezuela, la reforma agraria fue solo simbólica. 
Argentina, Uruguay, siguieron otro camino. No existía el sistema latifundio tradicional-precarista por circunstancias diferentes en la colonización. La gran propiedad pampeana se creó con la conquista en 1879 del "desierto pampeano" todavía ocupado por unos 20.000 indios. La guerra fue financiada con capital extranjero y con la venta de obligaciones por parte del estado. Ya antes de la ocupación se entregaron 3,8 millones de has. a 438 propietarios y la concesión de propiedades de 2.500 y 10.000 has. fueron frecuentes. Cuando llegó la gran migración de españoles e italianos a finales del siglo XIX, la tierra pampeana estaba ya ocupada, como lo estaban las tierras de Sao Paolo. Se propagó entonces el sistema de arriendo y medianería sobre las grandes propiedades. Actualmente en la región pampeana el cultivo directo oscila entre el 30-34 \% de la tierra, el arrendamiento alrededor del $55 \%$ (a veces solo el $25 \%$ ) y la aparcería entre el 11,15 y $42 \%$ según zonas. Las superficies arrendadas oscilan entre 100-625 has y a veces, superan las 1.000 has por explotación. La reciente propagación del cultivo mecanizado de la soja transgénica ha creado lo que los argentinos llaman el "desierto verde". Son explotaciones de tipo farmer, con solo algunos obreros eventuales en las mayores explotaciones.

Un breve comentario a estas diferentes vías de transformación agraria nos orienta sobre la situación actual. Presentamos dos ejemplos de los que escogieron la vía de "modernización" sin reforma agraria (Brasil, Colombia) y cuatro ejemplos de reforma (Chile, Perú, México, Bolivia).

\section{BRASIL Y COLOMBIA, LA VÍA DE LA "MODERNIZACIÓN"}

\subsection{Brasil}

Había un dualismo entre las dos regiones costeras, el NE y el Sur (Sao Paulo). El interior estaba casi vacío

En el sur se cultivaba café, algodón, ganadería y se iniciaba el de la caña de azúcar. Había recibido una poderosa inmigración a finales del XIX de portugueses españoles e italianos y en el espacio agrario se habían establecido relaciones laborales bajo contrato

En el NE, entre los grandes propietarios, cultivadores tradicionales de caña de azúcar, persistía la mentalidad esclavista y se mantenía el corvao o trabajo gratuito en la hacienda del señor. Entre 1950-64 se multiplicaron las ligas campesinas exigiendo suprimir el corvao y tener contratos estables como en el sur. Al mismo tiempo los propietarios, ante la competencia de los nuevos cañeros del sur, querían modernizar sus haciendas lo que conllevaba expulsar a sus antiguos colonos. Fruto de la agitación y bajo las ideas de Punta del Este 
había una tendencia a que se entregase la tierra a esos precaristas. El gobierno promulgó en 1964 el "estatuto de la tierra" que fijaba los arriendos, salarios mínimos y eliminaba la precariedad (la renovación del contrato al arbitrio del señor). Todo en medio de grandes tensiones.

Pero ese año, los militares tomaron el poder y se mantuvieron hasta 1985. En esos 20 años se dio la gran transformación industrial y agraria del país.

El resultado de la industrialización fue reducir la importancia relativa de la agricultura. Antes, el $75 \%$ de las exportaciones eran agrícolas, al dejar el poder solo eran el $47 \%$. El país había iniciado su industrialización durante la crisis mundial de los años treinta (Volta Redonda), a lo que ayudaba la gran abundancia de minerales (primer productor de Iberoamérica de mineral de hierro de alto contenido de metal, abundancia de bauxita y reservas petroleras que le hacen hoy día autosuficiente). La industrialización se localizó preferentemente en el sur en un triángulo entre Bello Horizonte-Curitiba-Santos, teniendo a Sao Paolo como núcleo principal. Y junto a la industrialización se iniciaron grandes infraestructuras para la colonización del interior vacío.

Para financiar la industrialización, además de los préstamos concedidos por el FMI, buscaron fondos con las exportaciones de los productos agrícolas. Por eso promovieron la modernización de la agricultura, que recibió créditos si era exportadora. Modernización-productividad-expansión territorial convirtieron a la agricultura a partir de 1975 en polo de desarrollo nacional, pero provocó una concentración de la propiedad en vez de su distribución. El resultado fue la expulsión masiva de precaristas en todo el país, por pasar al cultivo directo. Surgieron las ciudades dormitorio con los antiguos precaristas en espera de contratos para la recogida de la cosecha. Eso aumentó las desigualdades sociales.

Unos ejemplos para mostrar la profundidad de estos cambios.

En 1927, ante el exceso de azúcar en el mundo, Brasil había empezado a obtener alcohol de la caña para mezclarlo con la gasolina en los coches. En 1938, el $15 \%$ del carburante de los coches estaba mezclado con alcohol. En 1973 el precio del petróleo se disparó provocado por la guerra del Kipur en Palestina. Para evitar los gastos de la importación del crudo, se pasó a la construcción de coches con solo alcohol como combustible y en 1975 se fundó el Programa Nacional del alcohol. El estado dio créditos para extender el cultivo de la caña y crear grandes destilerías de alcohol. Se calcula que el gasto de esa protección, hasta 1985, alcanzó unos 16.000 millones de dólares. En 1983 salió de la fábrica el coche 1 millón con solo alcohol-etanol como combustible.

Las consecuencias sociales acompañaron a las económicas. Los fabricantes de coches tenían que asegurarse la producción de alcohol y controlaron las destilerías -que son gigantescas- y se aseguraron la producción de caña. Esta entró en un proceso industrial y de concentración en manos de firmas 
industriales. Los nuevos dueños buscaron la productividad y los precaristas y medianeros fueron expulsados.

En 1930 se cultivaban 400.000 has, casi todas en el NE. En 1980 se cultivaban 2.7 millones de has. En el 2004, eran 6 millones de has. y 498 millones de Tm. de azúcar. Para comprender lo que significan estas cifras se puede tener presente que Cuba produjo en 2002, 35 millones de Tm., Colombia 33 millones y México 47 millones. Solo la región de Sao Paulo produjo 359,5 millones $\mathrm{Tm}$. El aumento de productividad es llamativo: antiguamente, una ha. de caña producía 2.000 litros de alcohol. Hoy produce 6.000 .

Se emplean entre 230.000 y 400.000 asalariados temporales para la cosechas que los "testaferros" o contratistas empleadores buscan entre los antiguos precaristas. Las ligas campesinas de los años sesenta las eliminaron los militares, pero recientemente han surgido los Sindicatos de Trabajadores sin Tierra.

Actualmente con la eliminación de la mezcla de plomo en las gasolinas y, sobre todo, con el aumento del precio del petróleo, el estado da seguridad a los fabricantes de coches que el sistema de mezcla o de solo alcohol está garantizado.

En el resto de los cultivos agrícolas comerciales se dio igualmente la trilogía de la caña: modernización-productividad-expansión del cultivo, todo favorecido por la facilidad de préstamos para los productos comerciales.

Partiendo del sur, los cafeteros-algodoneros de Sao Paulo, los azucareros, los colonos alemanes del sur (Santa Catalina, Paraná), los agricultores de Minas Gerais extendieron sus cultivos por una frontera agrícola que se extiende hacia la Amazonia por el Mato Groso y Goias. A este frente pionero de expansión de cultivos comerciales, partiendo del Sureste, lo consideraron los militares como el sustitutivo de la reforma agraria. Hasta 1980 en 15 años entregaron 82 millones de has. De ellas 32 fueron puestas en cultivo para productos de exportación por propietarios medios tipo "farmer" americano sin obreros, con mano de obra familiar o por medianas empresas capitalizadas.

Unos ejemplos de esa expansión y productividad: En 2004 se produjeron 3,8 millones Tm. de algodón. En 1994 una ha. producía 1.390 Kg. y en 2004, $3.300 \mathrm{Kg}$.

En 1960 se cultivaban 200.000 has. de soja. En 1980 8,7 millones. En el 2003, 21 millón de has. con una producción de 51 millón de Tm. (En Mercosur, junto con Argentina -26 millones Tm. y Paraguay, 3,2 millones Tm. compiten con EE.UU. en cantidad)

En 1964 Brasil produjo 10 millones Tm. de maíz. En 2004, 48 millones Tm. En arroz, 13,2 millones Tm. en 2004. Café 2,4 millones Tm.

Naranjas: 2,2 millones en 1964, 7 millones en 1979 y 18,3 millones Tm. en 2004, en un millón de has. Es competidor con Florida y el primer exportador de zumo concentrado y congelado del mundo con 1,2 millones Tm. 
Si puede citar la mejora genética del café y aumento de su productividad o la producción de plátanos, de tomates. En cambio, los antiguos cultivos populares disminuyeron: la mandioca de 12 millones de has. paso a 1,2 millones

Al lado de esta expansión agraria asistida, con facilidades de crédito y de entrega de tierras, se dio otra colonización espontánea en el interior acompañando a la construcción de carreteras. Fue una colonización libre de minifundistas del NE, con cultivos itinerantes de subsistencia, pero a los que rápidamente se agregaron haciendas ganaderas capitalistas asistidas por el estado. Un dualismo que es persistente en América latina.

Esta colonización espontánea se había iniciado en 1960 al construirse la carretera que uniría la nueva capital Brasilia con Belem en el NE. En ese espacio vivían 100.000 hab. Siguiendo a la construcción de la carretera surgió una colonización espontánea minifundista y de subsistencia. La población pasó en esos años a 2,5 millones de habitantes.

Fue el preludio de lo que iba a ocurrir en la Amazonia con la construcción de carreteras al norte y sur del río. Se han producido dos procesos

a) Al lado de las carreteras se instalan por su cuenta pequeños agricultores. Queman bosque y establecen cultivos de subsistencia, que al agotarse la fertilidad del suelo a los pocos años, se convierte en itinerante.

b) Una colonización oficial. Se inició con la entrega de tierras, alimentos para seis meses, vivienda, etc., parecido al antiguo INE español de aquellos años. Pero, en cinco años solo se establecieron 3.000 familias. Al ritmo del crecimiento de la población, era insignificante. Rápidamente se cambió de estrategia. Se creó el SUDAM (Superintendencia de Desarrollo amazónico). El gobierno militar quería una ganadería exportadora de carne y se inició la entrega de enormes propiedades, cada una de un mínimo de 25.000 has. para ranchos ganaderos. La tierra se entregaba sobre coordenadas en el mapa y los nuevos propietarios expulsaron a los pioneros espontáneos que no tenían derechos de propiedad o los utilizan temporalmente para crear las granjas

El modelo de esta colonización lo había dado Ludwig que posee 2 millones de has. en la desembocadura del Amazonas. Repobló 90.000 has de árboles de origen asiático para pasta para papel, plantó arrozales, (8.000 trabajadores), saneó el espacio. Varias multinacionales han recibido enormes lotes: Brunyseel (holandesa): 200.000 has. Georgia Pacific (USA) 500.000 has. Toyamanka (Japón): 300.000 has. En Mato Groso: Volswagen, Nestlé, Liquigas, Good year etc.

En el año 2001, ante las numerosas pruebas de corrupción y desvió de dinero, el presidente Cardosa suprimió el SUDAM y lo sustituyó por el ADA (Agencia de desarrollo amazónico). En 2003, Lula resucitó el SUDAM sobre nuevas bases. 
El resultado de este proceso de apropiación de la tierra fue el siguiente:

- En 1940 había en Brasil 1.985.000 explotaciones que ocupaban 197,7 millones de has.

- En 1960 eran 3.338.000 explotaciones que ocupaban 249.9 millones has.

Su distribución: los de menos de 10 has. eran el $44,5 \%$ y tenían 2,4 $\%$ tierra. Los de más de 1.000 has. eran el 0,9\% y tenían el $44 \%$ de la tierra

- En 1985 la propiedad privatizada era de 374 millones de has. y los propietarios eran 5.800 .000

Los de menos de 10 has. tenías el 2,2\% de la tierra (8 millones has.)

Los de 100 a 500 has. tenían el $23 \%$ de la tierra (88 millones has.)

Los de 500 a 1.000 has. tenían el $11 \%$ de la tierra (41 millón has.)

Los de más de 1.000 has. (1\%) tenían el $45 \%$ de la tierra (189 millones has.)

El resto, eran propiedades pequeñas-medias, entre 10-100 has.

En 1998, 200 millones de has. se dedicaban a ganadería extensiva con 163 millones de cabezas de vacuno.

En el año 1985 se dio un cambio político en Brasil. Los militares dejaron el poder a un gobierno civil. Ante las tensiones creadas en los 20 años de dictadura militar, por las expulsiones de los precaristas, se decidió un "Plan de Reforma Agraria" que fue votado por el nuevo gobierno civil (Sarney) ese año.

Se daban cifras de más de 4 millones de campesinos sin tierra. Oficialmente se calculaba que los futuros beneficiarios de la reforma agraria votada sumaban un contingente de 6-7 millones de familias incluidos los "posseiros" (que tienen posesión de tierra, pero no la propiedad), los arrendatarios, aparceros, asalariados y minifundistas. Con estas cifras se planeó el asentar a 1,4 millones de familias hasta 1999 y expropiar 16,6 millones de has. Pero entre 1985-1994 solo se habían entregado 12,9 millones de has. a 150.000 familias. El proceso se aceleró entre 1995 y 2003, con la entrega de 23 millones de has. a 635.000 familias.

La elección del actual presidente Tula, de origen sindical, creó nuevas esperanzas, sin que hasta ahora haya logrado asentamientos numerosos. Contrasta el hecho de que en esos años, unas 400.000 familias minifundistas perdieron sus tierras y 800.000 asalariados su empleo. Se calcula que de 1885 al 2000, tres millones habían emigrado a las ciudades.

La presión por la tierra lanzó la idea, por parte del gobierno, del "Nuevo mundo rural", al mismo tiempo que surgía el movimiento de los Sin Tierra 
(MST) que ante la lentitud de los asentamientos, practica la ocupación de latifundios y exige su legalización posterior. Hasta el 2000, 440.000 familias habían ocupado grandes fincas. Son miles las familias de los MST que permanecen en el territorio, en enormes campamentos, esperando la concesión de tierras. De allí parten los grupos para invadir las grandes fincas. En 1996 había 50.000 familias en 270 campamentos.

El problema de los recientes asentamientos del estado y mucho más el de los latifundios ocupados por la fuerza, es la necesidad de ayudar a esos agricultores marginados, que no poseen técnica de cultivo, ni capital, el mismo fenómeno que ocurre en todas las reformas agrarias con el reparto de tierra. En Brasil a estas ocupaciones de fincas se les llama "favelización del campo". Se agrega el hecho de que muchos de los asentados provienen de otros climas y requieren técnica agrícola diferente de la conocida por ellos. Se necesita formación, infraestructuras, préstamos, canales de comercialización para que no sea simplemente agricultura de subsistencia. Todo eso requiere grandes ayudas financieras del estado, en un país cuya deuda exterior, en el 2001 era de 226.362 millones de dólares

El resultado de este largo proceso es una agricultura a dos velocidades que complica socialmente el agro brasileño, entre unos agricultores bien preparados para el mercado internacional, promotores de la agroindustrialización, y la llaga social de los Sin Tierra o de los minifundistas de subsistencia, demasiado numerosos, para quienes un apertura de las importaciones baja los precios y les provoca una pobreza bajo el límite.

Como decíamos al comienzo del artículo, un hecho es fundamental para comprender todo esta compleja evolución (de desarrollo y de injusticias sociales) de la agricultura brasileña que impresiona por su amplitud y dureza: la evolución de la población. En 1950 Brasil tenía 50 millones de habitantes. El censo del 2000 dio 170 millones de habitantes. Nos hacíamos antes una pregunta espontánea: que ritmo continuado de crecimiento económico tiene que lograr un país para que, partiendo de la pobreza, pueda elevar el nivel de vida dentro de ese crecimiento poblacional tan impresionante.

En 1992, el presidente Lula creó un ministerio "desarrollo social y combate al hambre" y se crearon 32 programas sociales bajo el título de "hambre cero" para todo el país. Dentro de la dificultad de obtener datos totalmente fiables, que no sean solo propagandísticos, se habla de 4 millones de empleo creados en los tres últimos años y de que del nivel de 35,8\% que vivía debajo de la línea de la pobreza en 1992, se ha pasado al $25 \%$ en el 2004.

Pero la tensión por la tierra continúa, como lo demuestra el asalto al parlamento, en los primeros días de junio del 2006, por el Movimiento Liberador de los Sin Tierra (MLST) rama radical escindida de los MST. 


\subsection{Colombia}

Tres cadenas montañosas, separadas por dos valles, constituyen el armazón del país. Allí se encuentra la capital. Al norte y al oeste, las tierras llanas de las costas atlántica y pacífica. Al este la llanura amazónica.

El caso colombiano es una repetición, con variantes propias, del brasileño.

Prácticamente no hubo reforma agraria y se promovió una colonización, tipo frontera, al mismo tiempo que se modernizaban las grandes explotaciones y se desarrollaba una mediana propiedad para productos de exportación. A partir de los sesenta se produjo un avance del sector moderno de los productos de exportación: plátanos, azúcar, algodón, tabaco, café. Pero se perpetuaron las mismas desigualdades y una tensión social, que ha desembocado en guerrilla, secuestros, extorsiones, que llenan de inseguridad al país. Y todo lo ha complicado la expansión de los cultivos de coca y el poderoso grupo de los narcotraficantes.

A raíz de la "Alianza para el Progreso" de Punta del Este en 1961, se elaboraron planes de reforma agraria para la liquidación de los latifundios y su división en propiedades medias, tipo "farmer" que, además de tierra, recibirían créditos y tecnología. Pero entre 1961 y 1973 hubo expulsiones masivas de precaristas y se concentró más la propiedad. Las explotaciones de más de 200 has. habían aumentado en 3,5 millones de has. y tenían las mejores tierras. La necesidad de proteger los productos de exportación de estas propiedades, decidió al gobierno a desistir del reparto de tierras y promover, como en Brasil, la colonización de las zonas vacías del interior. Se establecieron dos frentes pioneros, uno en el valle medio del Magdalena $(50.000 \mathrm{~km} 2)$ y otro en la inmensa selva amazónica colombiana (50 \% del territorio nacional).

Pero el estado no controla esas zonas y la colonización de tierras vírgenes (la frontera) ha reproducido la misma desigualdad en la tenencia de la tierra (grandes propietarios y minifundistas) donde se impone la ley del más fuerte. Los grandes propietarios crean milicias para su defensa. Faltos de comunicaciones, en unos suelos frágiles, como los de la Amazonia, el cultivo más rentable para los minifundistas es el de la coca. Se extendió el cultivo de marihuana-coca-amapolas (éstas para heroína) que caen bajo el dominio de las organizaciones del narcotráfico y de la guerrilla que impone su impuesto de guerra. No hay que analizar, por conocida, la perturbación en que la guerrilla y el narcotráfico han sumergido a Colombia.

Fuera del frente pionero, en las zonas tradicionales de cultivo y para suavizar la falta de reforma, se aplicó desde 1975 el DRI (desarrollo rural integrado) a las pequeñas explotaciones que se dedican al cultivo de productos de consumo interno, mientras que las grandes explotaciones se dedican a cultivos de exportación. Mac Namara siendo director del Banco mundial había 
propuesto, en 1973, en Nairobi, ayudas al desarrollo de la actividad aldeana. Colombia se acogió a él en 1974. Se pretendía formar una élite de pequeños propietarios, como grupo dinámico, dándoles medios para integrarse en el mercado. Se trataba de un policultivo de judías, maíz, trigo, patatas, mandioca, todos de consumo interior. La Caja Agraria proporcionaba créditos, aunque muy caros (18\% de interés) y con la obligación de aplicar la tecnología propuesta por el banco, algo parecido a lo que veremos en las cooperativas de las reformas agrarias..

Había un millón de minifundistas. De ellos, 252.000 eran cafeteros exportadores que se les excluyó. De los 720.000 restantes se eliminó a los de menos de 3 has. (por insolventes), lo mismo que a los asalariados. Por sucesivas limitaciones, solo 23.000 explotaciones se beneficiaron de los créditos. Fue un resultado muy pobre.

A partir de 1985, como en Brasil, se elaboró un Plan de Reforma agraria, prolongación del DRI para lo cual se buscaron ayudas del exterior. Además se elaboraron planes para repartir tierra a 721.000 familias durante 16 años, en dos períodos, en el primero 4,5 millones de has. y a partir de 1994, otros 6 millones. Pero la tierra a repartir, la compraba el estado y sin medios financieros para esa operación, solo se entregaron 120.000 has. a 4.500 familias.

Entre 1991 y 1995 la proporción de pobreza rural pasó de ser el $65 \%$ al 72\%. Reducido a cifras, en el 2006, de los 15 millones de campesinos, 8,5 millones viven en la pobreza y 3,3 millones en la miseria. En la campaña para la presidencia, ya terminada, se ofrecieron propuestas difíciles de cumplir, como el reparto de 4 millones de has. adquiridas con el dinero del narcotráfico o la violencia. Se calcula que la violencia ha desplazado a tres millones de pequeños propietarios que abandonaron sus tierra. La campaña presidencial afloró cifras impresionantes, aunque situadas dentro del contexto de una campaña electoral: 655.000 familias campesinas sin tierra, 2.250.000 minifundistas $(58 \%)$ de menos de 3 has. Frente a esas cifras, 2.428 terratenientes poseen el $53 \%$ de la tierra registrada.

La población había pasado de 12,5 millones en 1950 a 41,2 en el 2000. Se triplicó en 50 años.

\section{LOS INTENTOS PARA DESARROLLAR LA AGRICULTURA MEDIANTE REFORMAS AGRARIAS}

Hay dos modos de realizarla: Reforma agraria liberal y reforma agraria marxista.

En la primera, solo hay trasvase en la posesión de la tierra. El sistema de mercado permanece, pero socialmente es más justo. El autor de la reforma es 
el estado y la establece por ley. El antiguo propietario puede reservarse una cantidad establecida por la ley y se le indemniza, al menos teóricamente, la parte expropiada, pero en la práctica apenas se indemniza. El proceso es: el propietario entrega al estado la tierra expropiada que éste distribuye a los agricultores beneficiarios de la reforma, que deben pagar, en teoría, anualidades sobre el valor de la finca, anualidad que el estado devuelve al antiguo propietario. En realidad, esto último no se cumple.

En la segunda, la agricultura es un apéndice de la planificación económica del estado. Se realiza por decisiones exteriores a la agricultura. La propiedad y el mercado lo controla el estado.

Las reformas agrarias que se analizan en este artículo son reformas liberales. Se prescinde, a pesar de su importancia, de la de Fidel Castro en Cuba que es de carácter marxista o la del sandinismo en Nicaragua.

\subsection{Reforma agraria en CHILE}

Bajo el punto de vista climático, Chile consta de tres grandes regiones: En el norte, el desierto de Atacama, donde el cultivo solo es posible mediante el regadío con el agua que desciende de los Andes. Fue incorporado a Chile en la guerra del salitre en 1879-83. La zona central, de clima mediterráneo, que posee las mejores tierras de cultivo. Allí se encuentra la capital. El sur, de clima oceánico, zona de bosques, cuyos habitantes -araucanos, hoy mapuches- lucharon por su independencia varios siglos. A partir de la conquista del territorio por el ejército chileno (1883) se colonizó el sur de Chile.

Como en toda Iberoamérica la tierra estaba mal repartida. En 1955: el 7\% de los propietarios grandes y medianos controlaban el $81 \%$ de la tierra y el 80 $\%$ de los pequeños propietarios sólo tenían el 8,4\% de la tierra.

En 1965, al iniciarse la reforma, la distribución de la propiedad era la siguiente:

\begin{tabular}{|c|c|c|}
\hline Explotaciones & $\mathrm{N}^{\mathrm{o}}$ de propietarios & Tierra acumulada \\
\hline Menos de 10 has. & 156.708 & 437.000 has. \\
\hline de 10 a 100 has. & 74.120 & 2.348 .000 has. \\
\hline de 100 a 1.000 has. & 19.333 & 22.290 .000 has. \\
\hline
\end{tabular}

Además, 700 tenían más de 5.000 has. por explotación para ganadería en estepas.

Aunque estas cifras son engañosas, pues mezclan tierras de regadío, buenas tierras de secano con grandes extensiones de tierras pobres o de eriales estériles para pastos, la realidad es que había 400.000 agricultores sin tierra. 
Por eso todos eran conscientes entre 1928 y 1955 que era necesaria una reforma agraria. Se creó la Caja de Colonización agraria con resultado decepcionante, pues solo se establecieron 1.000 explotaciones en tierras del estado.

Después de Punta del Este (1961) el gobierno de Alexandre dio en 1962 la Ley de Reforma agraria, pero solo expropiaba tierras abandonadas o mal explotadas. Según la ley "nadie podrá ser privado de su propiedad - salvo por razones de utilidad pública- y con indemnización, según el valor comercial de la tierra".En dos años (1962-64): 63.962 has se entregaron a 1.432 familias.

Por eso se puede decir que la reforma agraria chilena se inició con el gobierno de la democracia cristiana de Frei en 1964. Necesitó tres años de discusiones en el parlamento para modificar la ley anterior. (Frei no tenía mayoría absoluta). Pero en 1967 se aprobó la reforma donde intervino un ideólogo, Chonchol, que había participado en la reforma de Cuba.

Para dinamizar la reforma se aprobó la ley de sindicalización agraria a fin de concienciar sobre la reforma a las masas campesinas. Se estableció como límite de propiedad 80 has. de regadío o su equivalente en secano y 500 has. en colinas de secano (peores tierras). Pero muchos latifundistas habían dividido sus tierras en los tres años anteriores.

La promesa de Frei era distribuir la tierra a 100.000 familias en lo que se llamaron asentamientos. Pero a los tres años, se habían repartido 3.433.000 has. en 25.000 asentamientos comunitarios. Solo las familias que trabajaban en la finca permanentemente entraban en los "asentamientos". Pero ellos luego, emplearon obreros temporales que los consideraron como nuevos explotadores.

Tres instituciones dirigían la reforma: la CORA (Corporación de reforma agraria) para infraestructuras, el INDAP (Instituto de desarrollo agropecuario) y la ECA que promovía la comercialización. Los asentamientos eran islotes privilegiados y aislados, todavía comunitarios, pero con la promesa del paso a propiedad individual.

En 1971 llegó al poder la Unidad Popular de Salvador Allende (también sin mayoría absoluta). Chonchol se incorporó a la Unidad Popular y dirigió la reforma. El umbral se limitó a 40 has. regadas. Chonchol, en poco más de dos años, repartió 5,5 millones de has. y se alcanzó la promesa de las 100.000 familias en los "Centros de Reforma agraria". En ellos se agrupaban las tierras de varios dominios para formar una unidad económicamente rentable y se integraban en ellos, sin distinción, a los trabajadores fijos y a los eventuales. Se organizó un pool de maquinaria agrícola para cada unidad productiva. Los centros debían estar dirigidos por una asamblea que elegiría democráticamente a sus representantes, pero su financiación estaba en manos del banco del estado al cual debían presentar un plan de explotación.

Los antiguos "asentados" reclamaban que las tierras ( 25 has. de media) les fuesen entregadas, según promesas del gobierno anterior (de Frei), como 
propiedad privada. Los trabajadores de los centros de Reforma querían también su pequeña parcela particular. Se acusó a Chonchol de crear granjas del estado al modelo ruso. Había una indefinición en el pensamiento de Chonchol que bloqueado por la derecha y por la izquierda radical, que quería actuaciones más drásticas, dimitió en 1973 poco antes del golpe de Pinochet. Como reconoció Chonchol en sus artículos posteriores, quedaban todavía en esa fecha 300.000 agricultores sin tierra

Durante el gobierno de los militares hubo situaciones confusas: unas tierras se devolvieron a sus antiguos dueños, otras quedaron definitivamente entregadas a los nuevos propietarios, pero un hecho fue fundamental para el futuro: se pasó de los centros comunitarios de la reforma a la propiedad individual con posibilidad de comprar y vender la tierra. Eso facilitó la introducción de los agricultores en los mecanismos del mercado que, al llegar la democracia, ha dado sus frutos

Hoy día la tierra está repartida entre 102.766 pequeños agricultores con agricultura de subsistencia, 176.034 pequeños agricultores empresariales, 17.005 empresarios medios y 9.399 grandes empresarios.

Con la llegada de la democracia se multiplicaron las ayudas al campo, se crearon agrupaciones de pequeños empresarios y se llegó a un desarrollo rural, sobre todo en el sector agroalimentario y la exportación. La estabilidad del gobierno y su política aperturista en todo el ámbito de su economía ha atraído inversiones extranjeras (más de 4.000 empresas) el segundo país después de Irlanda. Entre 1990 y 2003 el índice de pobreza total pasó del $38 \%$ al 18\% y la pobreza extrema ha bajado de $13 \%$ a $4,7 \%$. Chile está asociado a Mercosur y tiene un tratado bilateral con EE.UU.

\subsection{Reforma agraria en PERÚ}

Sus 1.285.000 Km2 están divididos en cuatro regiones naturales: La costa progresivamente más seca hasta llegar al desierto integral en la frontera con Chile. Se cultiva mediante riego en las valles que arrancan de la cordillera. $\mathrm{Al}$ este, la sierra, con altiplanos interiores, el núcleo del imperio incaico. Más al este, el descenso boscoso a la Amazonia -la ceja de montaña- y los llanos amazónicos.

En 1961 las explotaciones de menos de 3 has representaban el $84 \%$ del total y poseían el 1,6\% de la tierra. El 1,2\% de las explotaciones poseían el $75 \%$ de la tierra. Todavía más que en Chile estas cifran engloban tierras de muy diverso valor, pues muchos pastos del altiplano, pertenecientes a grandes haciendas ganaderas, eran muy pobres. Era en la costa donde coexistían un minifundismo extremo, mediana y gran propiedad en los espacios regados. 
En la costa predominaba, en el norte la caña de azúcar y el arroz, y en el sur, el algodón. En los regadíos del norte, 10 explotaciones poseían 85.000 has dedicadas a caña de azúcar. Eran complejos industriales -uno, la empresa Chicana, con 14.000 has- tenían sus escuelas, dispensarios, sindicatos, etc. Algo semejante, en cuanto a concentración, pero en menor escala, existía en las explotaciones de algodón (aquí predominaba el yanaconaje o mediero) y en parte de los cultivos de arroz. En la costa se riega un total de 1.700.000 has.

En el altiplano, los grandes latifundios (de hasta 400.000 has, e incluso una de un millón de has) coexistían - con luchas - con las comunidades indígenas. Dentro de los latifundios, en los valles de descenso al llano, había una lucha constante entre patronos y colonos-arrendires-allegados que pretendían librarse de la obligación de trabajar gratis varios días en la hacienda del señor que les suministraba en precario esa tierra, mientras que los propietarios deseaban modernizar expulsando a los arrendires, allegados y lo mismo el ganado de los colonos. El altiplano era un hervidero de luchas sociales, por las invasiones de las comunidades indígenas en las tierras de los latifundistas, huelgas de los arrendires (en el Valle de la Concepción) y la multiplicación de sindicatos agresivos

Frente a la gran acumulación de tierras en pocas manos, frente a un minifundismo extremo y abundante peonaje sin tierras, la reforma se consideró Desde 1961 se habían dado varias normas preparando la reforma, que se inició en 1964 con el gobierno de Belaunde (1963-68). Fue una reforma selectiva. Si el propietario cultivaba sus tierras en directo, podía retener 150 has. en tierra regada, 300 en secano, pero susceptible de ser regado, 450 has. en terrenos no regables y 1.500 has. en pastos. Si no la cultivaba directamente la finca se repartía a los arrendires a razón de 15 has. en el litoral y 30 en la sierra. En la sierra las condiciones eran diferentes según su calidad. El bosque no era expropiable si estaba cultivado el tercio de su superficie.

Se respetaban las grandes explotaciones cañeras de la costa con sus azucareras, pues eran los cultivos principales de exportación y su expropiación podía disminuir la productividad. En realidad pretendía suprimir todas las servidumbres personales de un régimen tipo feudal.

De hecho, entre 1964 y 1968 solo 600.000 has fueron distribuidas en la costa, pero en la sierra se eliminó el poder del grupo de latifundistas ganaderos.

En 1969 llegó al poder el general Velasco Alvarado e hizo una reforma radical, a nivel nacional, pues afectó también a las grandes empresas industriales cañeras de la costa. Si la ley de 1964 había disminuido el poder de los latifundistas de la sierra, la nueva eliminó a la oligarquía de la costa.

Las grandes plantaciones de la costa mayores de 1.500 has ( 8 haciendas reunían cerca de 80.000 has.) se convirtieron en cooperativas, dominios au- 
togestionados por comités especiales que representaban a los trabajadores. Pero el estado tenía el control financiero y vigiló la producción.

La reforma, radical, venía desde arriba. Se suprimieron los sindicatos y le sustituyó una nueva organización, SINAMOS, como dinamizador de la reforma

Se distribuyeron 9,5 millones de has. a 429.000 familias que se beneficiaron, de algún modo, de la reforma, sobre un total nacional de 1.200.000 familias. Pero 143.000 beneficiarios, pertenecientes a comunidades indígenas, recibieron solo una pequeña ayuda. Hay que tener presente las limitaciones del clima: de estos 9,5 millones, solo el $13 \%$ estaba cultivado

La tierra no se entregó como propiedad individual a los beneficiarios, sino que se les agrupó en cooperativas, a fin de dotarles de crédito, dirigir las técnicas de cultivo e invertir en infraestructuras.

Dos fueron las modalidades principales de organización de las nuevas empresas asociativas:

- cooperativas agrarias de producción (CAP)

- sociedades agrícolas de interés social (SAIS)

Los CAP provenían de haciendas modernas de la costa con todas sus tierras, instalaciones, infraestructura, maquinaria, plantaciones y ganado. Los antiguos trabajadores estables se convirtieron en sus socios. Aunque en la sierra también se crearon CAP (en las tierras cultivadas) predominaron las SAIS con las tierras de los grandes latifundios o uniendo varios de ellos en una empresa. En la sierra los asalariados estables eran pocos, pero había un porcentaje grande de pequeños campesinos eventualmente asalariados, que cultivaban su pequeña parcela. Todos fueron agrupados en la SAIS.

Pero los antiguos latifundios de la sierra estaban rodeados de comunidades indígenas, en litigio con los latifundios cuyas tierras invadían periódicamente. Las comunidades solo parcialmente y de forma laxa se incorporaron a las SAIS. Los litigios continuaron entre las SAIS (que sustituyeron a los latifundistas) y las comunidades. Por otra parte las SAIS apenas recibieron dinero para mejoras. Fue solo un cambio de dueño.

Hay que agregar un tercer grupo, los "grupos campesinos". Eran los antiguos pequeños propietarios individuales, que recibieron un suplemento de tierras y se agruparon, para recibir créditos oficiales.

Quedaba un cuarto grupo, los antiguos propietarios, a quienes se les había permitido mantener una pequeña parte de su propiedad, con umbrales prefijados según el tipo de tierra. Estos pidieron créditos a la banca privada.

A partir de la reforma se inició un control económico, administrativo y financiero por parte del estado sobre los grupos reformados (CAP y SAIS), 
a fin de que no disminuyese la producción y se formasen técnicamente como agricultores. En los CAP, el estado controló la comercialización interna y externa del algodón con precios base, fiscalizó estrechamente el comercio del azúcar y monopolizó el crédito agrario a través del banco agrario. El agricultor no tenía libertad para elegir el cultivo, ni cómo producirlo. El banco agrario oficial zonificaba y aprobaba los cultivos, el plan de riego, la selección de semillas y las técnicas a principios de cada campaña. Estas limitaciones no existieron en los propietarios libres, antiguos propietarios afectados por la reforma y convertidos en propietarios medianos que, por disponer de capital propio o de créditos bancarios privados, pudieron implantar nuevas tecnologías, como riego por goteo, y establecer su selección de cultivos en función de la rentabilidad. Abandonando el algodón, plantaron frutales, hortalizas y extendieron el cultivo del arroz.

Los sucesivos presidentes que sucedieron a Velasco, aumentaron los regadíos de la costa, pero aunque oficialmente insistían en mejorar la reforma, se desentendieron poco a poco, en realidad por falta de medios. La reforma había sido más un cambio de propiedad, que una mejora de productividad y rentabilidad. Por eso a partir de 1980 perdió fuerza. La tendencia de los cooperativistas a privatizar la tierra y ser dueños de una parcela, llevó a promulgar una ley en 1991 y otra en 1995 que permitió la parcelación, la venta y compra de tierras y la formación de sociedades. Desapareció el banco agrario y las redes estatales de comercialización de los productos. Esto convirtió en poco tiempo a los antiguos cooperativistas de los CAP en minifundistas de 3-4 has. a veces en parcelas separadas. Como además ha sido lento el proceso de inscribir la parcela en el registro de propiedad (le llaman saneamiento) cerca de 2/3 de estos minifundistas carecen de marco legal para pedir créditos.

Actualmente existen cuatro tipos de agricultores:

- propietarios medios (los antiguos propietarios que pudieron retener una parte de sus tierras. Cultivan unas 40.000 has de frutales y hortalizas (ampliables a 200.000 has) con técnicas modernas y buenas redes comerciales.

- el grupo más numeroso, los parcelistas que provienen de la disolución de los CAP de la reforma. Cultivan productos comerciales, alrededor de 1.200.000 has de algodón , azúcar, arroz, café. Tienen unas 3-4 has, a veces en lotes dispersos. Desaparecido el banco agrario, que les suministraba créditos y el organismo estatal de la comercialización, son en general pobres. Han logrado ya el título de propiedad que le faculta el tener capacidad para pedir créditos y sus productos los comercializan redes privadas, organizadas a veces por los antiguos propietarios. Entre ellos hay emergentes y pobres. El total de los regadíos costeros es de 1,7 millones de has. 
- minifundistas tradicionales con cultivos para el comercio interior.

- Otros grupos marginales de subsistencia.

- Las antiguas grandes cooperativas azucareras costeras que se encuentran descapitalizadas.

Dejando que funcionasen las leyes del mercado, los productos importados hundieron los precios con pérdidas para los agricultores de productos de consumo interior. La situación generalizada es de pobreza, fuera del sector dinámico de los medianos.

La población era de 7,6 millones de habitantes en 1950. En el año 2000 era de 26 millones

Abandonada la reforma, un frente pionero extendió los cultivos en el llano amazónico que representa el $59 \%$ del país. Pero faltos de comunicaciones para dar salida a sus productos, se ha extendido el cultivo de la coca que secularmente se cultivó en los valles que descienden al llano. Con ello Perú ha entrado en una doble dinámica: las prohibiciones exigidas por EE.UU y la defensa del cultivo de la coca como, un producto nacional, por los cocaleros. Recientemente el gobierno local del Cuzco legalizó el cultivo de la coca (siempre se cultivó en el Valle de la Concepción) que el gobierno de Fujimori había intentado erradicar, sin éxito. En la lucha por obtener la presidencia del gobierno, el candidato derrotado, Umanta, prometía la legalización del cultivo, naturalmente con restricciones. Hay que tener presente que, en las zonas indígenas, cocaleras, alcanzó el 80\% de los votos.

\subsection{Reforma agraria de MEXICO}

El territorio mexicano tiene $1.960 .000 \mathrm{~km} 2$. Posee tierras cálidas, tierras templadas y tierras frías en las altas mesetas. Desiertos en el norte y bosques tropicales en el sur.

México es un caso especial en la evolución de la agricultura iberoamericana, aunque no en sus formas. Su reforma se adelanta en el tiempo (antes de la revolución rusa y de las reformas agrarias de los países del este europeo, que siguieron a la primera guerra mundial), se ha prolongado durante 80 años y alcanzó una amplitud excepcional. Entre 1917-1994 se entregaron 100,9 millones de has. a 3.459.000 beneficiarios. Ante estos datos palidecen todas las restantes reformas americanas y las de otros países.

El origen fue también peculiar, fruto de una guerra civil de siete años que causó un millón de muertos, iniciado todo, en 1910, por Madero, gran propietario del norte, contra 34 años de dictadura de Porfirio Díaz exigiendo que se devolvieran a las aldeas sus tierras usurpadas. Pero todo cambió con la revuelta de Pancho Villa entre los caballistas del norte y Zapata entre los 
obreros de las grandes empresas azucareras del sur, donde lanzó la idea "la tierra para el que la cultiva". Los motivos: Unas 8.000 grandes explotaciones +3.000 haciendas ganaderas del Norte, controlaban la tierra. Ejemplos de esta gran explotación eran la de R.Hearst, dueño de la gran prensa americana, que tenía 1.000.000 has. en Chihuahua o Luis Terrazas que, en 16 haciendas, tenía un total de 2,5 millones de has. de pastos o 32 hispano-cubanos que controlaban el tabaco del Valle Nacional. Trece haciendas controlaban la producción azucarera. La población era de 15 millones, el 80 \% rurales

En 1917, terminada la guerra civil, la constitución estableció que la propiedad de la tierra y el agua pertenecían a la nación y que el estado tendría siempre el derecho de imponer a la propiedad privada las modalidades que dicte el interés público. Se reconstruyó el ejido, como bien colectivo de la propiedad rural, declarado no enajenable. Los ejidatarios tendrían el usufructo de sus pequeñas parcelas que serían invendibles. Cada ejido englobaría alrededor de 25 parcelistas que tendrían 4 has. en regadío y 8 has. en tierras comunales. No se permitirían los latifundios, pero se respetaba la propiedad privada hasta 100 has. en regadío y 200 has. comunales. Sobre la estepa se aceptaban los lotes de 5-10.000 has. para ganado.

La reforma tuvo poca importancia hasta 1936. Hasta esa época se habían repartido 10 millones de has. a 980.000 beneficiarios pero en su mayor parte de pobres pastos. México se recuperaba del millón de muertos de la guerra y de la gran mortandad de la gripe española en 1918. Huyendo de la guerra, campesinos del sur habían emigrado a las ciudades y los del norte, a EE.UU que pedía brazos con la guerra mundial. En 1930 México tenia 16,5 millones de habitantes y 600.000 braceros vivían en EE.UU. Pero en esa fecha a raíz de la depresión mundial, 400.000 braceros mexicanos fueron reenviados desde EE.UU. Ellos exigieron la aplicación de la reforma con huelgas y movilizaciones.

En 1934 fue elegido presidente Cárdenas que decretó una reforma radical. En su mandato entregó 20 millones de has. a 765.000 beneficiarios y lo más importante, fueron repartidas las mejores tierras. Se inició por la Laguna de Torreón, gran llanada fértil dedicada al algodón. En 45 días agrimensores, agrónomos y policías, cuadricularon la llanura y entregaron a 300 ejidos un total de 147.000 has. Los 20 antiguos propietarios conservaron 150 has. cada uno, en total 3.000 has.

Ese modelo se aplicó en los dos años siguientes a muchas de las grandes haciendas intactas hasta entonces, como las haciendas de sisal en Mérida (controladas por unas cincuenta familias), las tierras azucareras en Sinaloa, los arrozales de las haciendas de Dante Cussi (unas 200.000 has.), los campos de algodón del Bajo Colorado, las haciendas de pulque (bebida obtenida del agave) en el nordeste de México. Eran zonas de gran productividad. Como la 
dificultad para el mantenimiento del ejido iba a provenir de la falta de capital, se creó el Banco Ejidal en 1936. Fue una reforma radical, planificada, financiada. Eso le dio prestigio nacional.

Se formaron, como 30 años más tarde en Perú, dos estilos de organización agraria. Uno dirigido por el banco ejidal que -al suministrar máquinas, abonos, semillas seleccionadas- inició un control férreo de los ejidos para mantener y relanzar la producción. A su lado, los agricultores expropiados -de propiedad media- que acudieron a los bancos privados para modernizarse. Los dos grupos, con diferentes estilos, iban a formar un frente pionero de la puesta en cultivo de tierras vírgenes, hacia el sur tropical y hacia el norte más seco que necesitaba multiplicar los regadío. El Estado construiría carreteras, pantanos y canales en el norte y daría concesiones de tierras comunales en el sur. Por principios revolucionarios el estado hubiera querido que los nuevos repartos fueran exclusivamente para ejidos, pero no tenía capital suficiente y tuvo que aceptar la incitativa privada.

Se inició la expansión en 1946 con el presidente M. Alemán. Mientras se creaban nuevos ejidos, donde los jóvenes de las aldeas recibían tierras (en 1955 se compró en el norte la hacienda de los Hearst, de 1 millón de has. de buenos pastos en Chihuahua y se instalaron 1.100 familias), los rancheros privados obtuvieron la mitad de las tierras vírgenes en el sur tropical que modernizaron con plantaciones de café, caña de azúcar, algodón y ganadería seleccionada, todo para la exportación.

A partir de López Mateos (1958), se priorizó de nuevo la reforma. Las nuevas tierras, regadas con gasto del estado, serían para los nuevos ejidos. El entregó 16 millones de has a 245.000 ejidatarios y Díaz Ordóñez entre 19641970 repartió 19,5 millones a 350.000 ejidatarios

Pero la capacidad financiera del estado era menor. Parte de los nuevos ejidos eran antiguas haciendas ganaderas, sin ninguna mejora. Por ejemplo, en Sonora, en 1959, se compraron a propietarios americanos, 266.00 has y 29.000 bovinos que se entregaron a 7 ejidos. Para su mejora, el estado se limitó a construir pozos para dar agua al ganado.

Hacia 1970 habían aparecido dos tendencias. Unos exigían que se hiciesen kolhozes y sovhozes al estilo ruso y hablaban de que la reforma había sido saboteada, al permitir, desde el presidente Alemán la entrada en las nuevas tierras a la propiedad privada. Además los economistas decían que el reparto había beneficiado a los propietarios que conservaban una parte de su antigua hacienda, que la habían modernizado y alquilaban tierras ejidatarias. Así, el $85 \%$ de las explotaciones -es decir casi todos los ejidatarios y pequeños propietarios- producían el $15 \%$ de los cultivos comerciales, y el $15 \%$ de las explotaciones individuales medias suministraban el $85 \%$ de la producción comercial (exportación y comercio en las ciudades). 
Se puede comprender esto por el funcionamiento de los ejidos, pues el proteccionismo del banco ejidal era excesivo y provocaba deserciones. Los autores mejicanos describían, como ejemplo, el funcionamiento del banco ejidal en los cultivos de algodón de la Laguna de Torreón, primer reparto exitoso de Cárdenas. Los campesinos debían asociarse en pequeños grupos, como condición para obtener créditos y tenían que aceptar la estrategia tecnológica que imponía el banco, diseñadas por su cúpula burocrática que se plasmaba en el Plan de Operaciones anual, en el que se determinaba la extensión a cultivar cada año y el número de ejidatarios que iban a recibir el crédito. El productor no decidía las semillas, el fertilizante, ni los herbicidas, ni el momento de su aplicación, todo lo decidía el equipo técnico del banco. El campesino no tenia contacto con el mercado, no afrontaba problemas, no tomaba decisiones, no elegía alternativas, no tenía capacidad para fijar el destino de sus excedentes.

Esto, que se estableció, como protección, en los primeros momentos al repartir la tierra a unos antiguos peones analfabetos, les impedía más tarde desarrollarse como campesinos auténticos. Y como la parcela del ejidatario era inalienable, muchos alquilaban su parcela y marchaban a trabajar a EE.UU. En 1970, la mitad de las parcelas no estaban cultivadas por el ejidatario, sino alquiladas a un empresario, a veces el antiguo propietario. Los empresarios medios, de propiedad privada, con técnicas modernas y mano de obra temporal obtenían altos rendimientos y controlaban a miles de pequeños ejidatarios a través de financiación, compraban a precios baratos su producción y la transformaban en procesos agroindustriales. Solo los ejidatarios del norte de 12-20 has de regadío se podían comparar con la propiedad media privada.

El gobierno era consciente de la descapitalización del campo, pero carecía de medios para modernizar los ejidos. Sabía que para financiar la modernización de los ejidos, debería aumentar los impuestos a otros sectores de la economía, algo impopular.

Entre 1940-1965 la agricultura mexicana satisfizo en alimentos la demanda interna y generó excedentes exportables para financiar las importaciones de bienes de equipo. Pero una crisis en la producción agrícola y el crecimiento de la población con la tasa de 3,5\% obligó a partir de 1970 a importar alimentos básicos

Se comprende, por eso, la reforma del artículo 27 de la Constitución que había establecido las normas de la reforma agraria. La reforma había aceptado la propiedad privada de 100 has regadas en las mejores tierras y su equivalente en el resto. Ahora, argumentando que ya no había latifundios y sí, en cambio, un minifundio atrasado e ineficiente (media de 4 has. o inferior), de que había ventas ilegales en los ejidos y que estaban descapitalizados, dio normas legales para la posible privatización del ejido, que dejó de ser inalienable y autorizaba que sociedades mercantiles pudiesen comprar y administrar tierras. 
Pero, al mismo tiempo, en 1970 había, a pesar del brutal crecimiento de las ciudades, más de 1 millón de aldeanos sin tierra que exigían continuar con el reparto. Por eso se prosiguió con la reforma y hasta 1994 se entregaron otras 30,87 millones de has. a 682.400 beneficiarios. Como se enumeró antes, entre 1917-1994 se habían entregado100,9 millones de has. a 3.459 .000 beneficiarios.

Los mejicanos aclaran, no obstante, que en los últimos 40 años esas extensiones no fueron del todo reales, pues a veces no llegaban a ejecutarse en su totalidad. Lo llaman "rezago agrario", retraso en la entrega. Además, el titular original había fraccionado, previamente, su hacienda entre sus hijos. En algunos estados el promedio de la parcela del ejidatario llega a ser menos de dos has por familia.

A pesar del volumen de tierras repartidas, unos dos millones de campesinos quedan fuera del reparto agrario. Hay que tener presente como elemento básico de reflexión que la población de México pasó de tener 25,7 millones en 1950 a 97,5 millones en el año 2000. Volvemos a preguntarnos, como en el caso brasileño, que ritmo continuado de crecimino económico se necesita para absorber esa masa de población. En los últimos años la presión demográfica se suaviza con la emigración clandestina a EE.UU tan preocupante para ese país que, próximamente, va a blindar la frontera con el ejército.

Hoy día se favorece al sector exportador y a la ganadería extensiva en detrimento de la agricultura campesina. Las grandes sociedades controlan esta comercialización. Por eso, han surgido nuevas rebeliones con el lema zapatista de Tierra y Libertad. Aunque se encuentran, en todo el país, grupos contrarios al neoliberalismo practicado por el gobierno, el más llamativo es el levantamiento del EZLN y las organizaciones indígenas independientes exigiendo la solución del "rezago agrario" en Chiapas. Hay nostalgia, en algunos grupos, de la vuelta a los antiguos criterios zapatistas.

Dentro del contexto de ese dualismo y doble velocidad de la agricultura, se comprende que el sector dinámico esté a favor del tratado bilateral de libre comercio que México firmó con EE.UU lo que supone un descenso en los aranceles y la entrada de capitales para la agrobussines, mientras que el ejidatario, que cultiva productos para el mercado interior, ve como la importación baja los precios en el mercado que, si bien favorece a los consumidores, deja sin beneficios a los pequeños cultivadores y el fruto de la reforma en los ejidatarios se desvanece

\subsection{La reforma agraria en BOLIVIA}

El país se encuentra donde las cuencas intramontañosas de los Andes son más amplias. Carece de salida al mar pues, en la guerra de 1879, Chile le arre- 
bató su territorio costero. La mayor parte de la población se concentraba, en 1950 , entre 2.500 y $4.500 \mathrm{~m}$ de altura. Allí y a alturas superiores, se encuentran los yacimientos mineros. El resto lo constituyen los llanos, pertenecientes, los del norte a la vertiente amazónica y los del SE a la vertiente paraguaya. Entre el altiplano y los llanos están las yungas o descenso al llano por un relieve de fuertes pendientes. La población era de 2.7 millones en 1950 de los cuales, 2 millones eran rurales y vivían en su mayor parte en el altiplano. En el año 2000 la población era de 8,2 millones, de ellos, 5,1 millón urbano y 3,1 rurales.

En el altiplano se encuentran la capital y las principales ciudades. Allí se concentraba la población en 1950. En los llanos orientales está Santa Cruz de la Sierra, ciudad rectora de esta zona, con una herencia colonial de oligarquía agraria de mestizos y blancos. Es la zona más rica de Bolivia, en agriculturabosques, ahora con gas natural. Antes estaba aislada, pero las comunicaciones modernas le han unido recientemente al altiplano, a Paraguay y a Brasil, lo que ha permitido la expansión del cultivo de la caña ( 86.000 has) y sobre todo de la soja (cerca de 1 millón de has), como prolongación del Matogroso brasileño. En 1950 este territorio no llegaba a tener 300.000 habitantes, pero en el 2000 superó los 2 millones un poco inferior a la población actual del altiplano.

El altiplano vivía principalmente de la minería, sobre todo la del estaño que era casi la única exportación del país. La población minera, muy numerosa, tenía sindicatos fuertemente organizados que imponían la ley al país. En 1952 llegó al poder Paz Estensoro. Un intento de eliminarlo del poder provocó una sublevación de los mineros que desarmaron al ejército y policía, se organizaron en milicias e impusieron la nacionalización de las minas y la reforma agraria.

La reforma en el altiplano fue especial, simplemente los antiguos colonos se repartieron por su cuenta las tierras y las dedicaron a cultivos de subsistencia, sobre todo las tierras cercanas al lago Titicaca, las más fértiles frente al resto del altiplano. El problema ha sido y lo es todavía que, después de 40 años, solo una parte de las tierras que, espontáneamente se apropiaron los colonos, está inscrita en el registro de propiedad (le llaman "saneamiento"). El resto carece todavía de reconocimiento jurídico.

A esa reforma del altiplano le siguió otra, también especial, hasta 1994 en los llanos, pero aquí lo peculiar fue que el reparto del estado fue a parar a la oligarquía agraria, ya existente, que recibió inmensos dominios de miles de has., lo contrario de una reforma típica, que elimina la gran propiedad.

Como resultado, en 1990, el $80 \%$ de los agricultores poseía el 2,5\% de la tierra, el $18,1 \%$ de medianos agricultores tenía el $12,1 \%$ de la tierra y el 1,8 $\%$ tenía el 83,\% de la tierra. Cifras comparables a las del Brasil después de la "modernización " de su agricultura, en Boliva después de su peculiar reforma 
agraria. Y solo una pequeña parte de esas propiedades medianas y pequeñas está cultivada, a pesar del avance imparable de la soja. En el 1994 se puso fin a ese reparto gratuito y se estableció para el futuro, la compra por concurso público.

Se calcula que 250.000 son campesinos sin tierra y que 1 millón solo tienen un minifundismo empobrecido. Se comprende la propuesta del nuevo gobierno (2006) de realizar una reforma agraria, pero esta vez con un rasgo étnico, el reparto se hará para los nativos. Se habla de 14 millones de has, o de 4,5 millones. Para realizarla tendrá que vencer las dificultades de los grandes propietarios, sobre todo los de Santa Cruz, antes todopoderosos.

Un problema es decisivo como ocurrió en México. Las propiedades libres de medianos y grandes propietarios se pueden vender y, por consiguiente, se pueden ofrecer en hipoteca, para obtener créditos e implantar nuevas tecnologías. Pero las pequeñas propiedades, recibidas gratuitamente en el reparto, y lo mismo las pequeñas propiedades tradicionales indígenas y las comunidades, están protegidas por la ley, no pagan impuestos y no se pueden enajenar, solo dentro de la comunidad y según sus normas, puede haber transacciones. Esta protección lleva a un anquilosamiento de la agricultura. En gran parte del altiplano, en los valles y el Chaco, zonas de comunidades indígenas, el agricultor solo puede pedir créditos sobre la garantía de una futura cosecha. El estado, que quiere suplir y conceder créditos, apenas tiene capacidad financiera y el agricultor tiene que ir a prestamistas con altos intereses. El exceso de protección les obliga a permanecer en su estado actual. Volvemos a estar ante una agricultura dual. Es de esperar que, por su procedencia del sindicalismo, el nuevo presidente podrá, con los beneficios del gas, ofrecer créditos a estos pequeños agricultores para su modernización.

En el altiplano la minería tuvo la mayor importancia. Pero al nacionalizarla languideció, por falta de inversiones, jornales altos que impusieron los sindicatos mineros y su baja productividad. El hundimiento de los precios internacionales del estaño en 1986, paralizó la explotación minera. El ejército se había reorganizado con armamento nuevo y obligó a cerrar la mayor parte de los yacimientos y privatizar el resto.

Una población de 60.000 mineros sin trabajo se desplazó a la selva amazónica y practicó el cultivo de la coca, fácil de cultivar para unos ex-mineros que no conocían técnicas de otros cultivos

El cultivo de la coca, que siempre se había cultivado en las yungas, se amplió y diputados (Evo Morales, hoy presidente) y sindicatos se opusieron siempre a su erradicación por parte de los americanos. Los ingresos provenientes del cultivo y exportación de la pasta son vitales para la economía de la nación.

En octubre del 2003, una revuelta de cocaleros y sindicatos, expulsó del gobierno al presidente Sánchez de Lozada y el nuevo presidente anunció in- 
mediatamente que se opondría a las fumigaciones como sistema de erradicación del cultivo.

Los funcionarios bolivianos consideran que los agricultores y ex-mineros cultivadores de coca, nunca se acomodarán al cultivo del palmito, la piña o el plátano que da solo un $20 \%$ del beneficio que se obtiene de la coca y exige diez veces más de trabajo, además de que estos cultivos están expuestos a enfermedades, mientras que la coca crece casi sin cuidados. Mientras que en la zona bien comunicada de Santa Cruz en Bolivia se extiende la soja y caña, en las zonas marginales el cultivo de la coca es para esos minifundistas crucial en su subsistencia

La intención del presidente Morales de legalizar el cultivo de la coca, en las yungas y Chaparé (donde secularmente se cultivó la coca) permitiendo a cada familia una extensión de $1.600 \mathrm{~m} 2$ hasta un total de 12.000 has, consensuado y controlado por los sindicatos, plantea un problema más a la agricultura sudamericana por la oposición frontal del gobierno de EE.UU. que recela de sus consecuencias.

Por eso habría que explicar el problema general de los cultivos ilegales en Sudamérica, con todas sus implicaciones, como fondo para un juicio definitivo de la agricultura iberoamericana. Pero su desarrollo alargaría excesivamente este artículo.

Como resumen se puede considerar que ninguna de las dos vías ha solucionado plenamente las contradicciones de los años cincuenta, tal vez por el aumento excepcional de su población. Lo que hemos llamado "modernización" que respetaba las grandes empresas, fue acompañada de unos problemas de marginación demasiado dolorosos e injustos. Tampoco se logró que desaparecieran los grupos marginados en los casos de reforma agraria, cuyo resultado fue la multiplicación de minifundistas sumergidos en la pobreza, al disolverse las cooperativas. Pero este último camino fue un proceso de dignificación del antiguo precarista, algo que consideramos de extraordinario valor. 
